FRBSF Working Paper 2002-17

\title{
Learning and the Value of Information: The Case of Health Plan Report Cards
}

June 17, 2002

\author{
Michael Chernew ${ }^{\#}$ \\ Department of Health Management \& Policy \\ Department of Economics \\ Department of Internal Medicine \\ The University of Michigan, \\ and NBER \\ Gautam Gowrisankaran \\ Department of Economics \\ University of Minnesota, \\ Federal Reserve Bank of San Francisco, \\ and NBER \\ Dennis P. Scanlon \\ Department of Health Policy \& Administration \\ Center for Health Policy Research \\ The Pennsylvania State University
}

Funding: This work was supported by a grant from the Agency for Healthcare Research and Quality (AHRQ), grant \# 1-R01-HS10050.

Acknowledgments: We are grateful to Tom Cragg and Bruce Bradley for providing the data for this study. We also acknowledge comments received from Dan Ackerberg, Pat Bajari, Scott Cardell, Tom Holmes, Phillip Leslie, Andrea Moro, Rob Porter, Gary Solon, Alan Sorensen, Frank Wolak, and seminar participants at Brown, Columbia, Dartmouth, Federal Reserve Bank of San Francisco, University of California at Berkeley, Davis, Los Angeles, and San Diego, University of Michigan, University of Minnesota, Stanford, and IHEA 2001 in York, UK. Finally, we appreciate editorial assistance from Anita Todd and programming assistance from Joe Vasey.

Disclaimer: The views expressed herein do not reflect those of the Federal Reserve Bank of San Francisco, the Federal Reserve System or of any other institution with which the authors are affiliated. 


\section{${ }^{\#}$ Corresponding Author:}

Michael Chernew, Ph.D.

Associate Professor

Department of Health Management and Policy

University of Michigan

109 S. Observatory

Ann Arbor MI 48109-2029 


\title{
Learning and the Value of Information: The Case of Health Plan Report Cards
}

\begin{abstract}
We estimate a Bayesian learning model in order to assess the value of health plan performance information and the extent to which the explicit provision of information about product quality alters consumer behavior. We take advantage of a natural experiment in which health plan performance information for HMOs was released to employees of a Fortune 50 company for the first time. Our empirical work indicates that the release of information had a small but statistically significant effect on health plan choices, causing 3.1\% of employees to switch health plans. Although consumers were willing to pay an extra $\$ 267$ per year per below average rating avoided, the average value of the information per employee was only $\$ 10$ per year. The relatively small impact of the ratings arises because the ratings were estimated to be very imprecise measures of quality. More precise measures of quality could have been more valuable.
\end{abstract}

Keywords: Information, Uncertainty, Health Plan Choice, Health Plan Quality, Managed Care.

JEL Classification: I11, D83, D12 


\section{Introduction}

In many markets, products vary substantively in terms of quality. Quality, however, often is not readily observable in these markets. Thus, it is uncertain what information is reflected in market equilibrium. Failure of markets to capture full information can result in lack of equilibrium or incomplete markets (Akerlof, 1970; Rothschild and Stiglitz, 1976) and may diminish welfare in a variety of ways (Stiglitz, 1989).

While economic theories identify mechanisms by which firms may gain reputations regarding quality, such as informal information networks, the characteristics of information make it hard to commodify. Information is hard to value before it is known and, in many settings, has public good characteristics. For these reasons, economists have long been interested in assessing the level of information in markets with new goods. A recent body of empirical work assesses the extent to which consumers learn from and value information (Ackerberg, 2001; Crawford and Shum, 2000; Erdem and Keane, 1996; Jin and Leslie, 2001; Milyo and Waldfogel, 1999). This paper contributes to that literature, by using a natural experiment design to estimate a formal learning model. To our knowledge, this is the first attempt to use a natural experiment to identify a Bayesian learning model.

In this paper we examine the impact of report card information in the market for health insurance plans. We make use of a natural experiment where employees received information on the performance of managed care health insurance plans. Using data on health plan choices from before and after the release of information, we estimate a Bayesian learning model that quantifies the prior information from reputation as well as the information from the report card ratings. This paper builds on previous research (Scanlon et al. 2002) and uses a similar, though more

\footnotetext{
${ }^{1}$ For example, Arrow (1963) comments on the "elusive character" of information as a commodity.
} 
comprehensive, data set. In contrast to the earlier work, this paper models the release of information in the context of a Bayesian learning model. This allows us to draw new conclusions. We quantify the value of the formally constructed and disseminated information, assess the relation between the ratings and consumers' prior beliefs regarding quality, and evaluate the extent to which information causes people to switch health plans.

As with all natural experiments, our estimated results directly reveal only values for the experiment that we are examining. Nonetheless, we feel that our results are of interest because they provide both direct evidence on the value of information for the health care sector and indirect evidence and methods that may be useful to other sectors of the economy where learning is important.

Understanding the role of information in the health insurance market is important since the market is notoriously plagued by a variety of information imperfections (Arrow, 1963). Quality, in particular, is both hard to verify and an important attribute of the health insurance market. Information about quality is particularly relevant in the market for managed care health plans. Managed care plans provide a mechanism for individuals to commit to a package of benefits and style of care before they realize their illness shock. Yet optimal adoption of managed care health plans requires information about the nature of care provided by each plan. Thus, report cards can add value by facilitating switching from traditional health insurance to the desired managed care plans, thereby avoiding the moral hazard problems of traditional health insurance.

\footnotetext{
${ }^{2}$ Researchers of many different sectors of the economy have been interested in understanding learning. For instance, recent studies have quantified the extent of learning for sectors ranging from semiconductors (Irwin and Klenow, 1994) to Indian agriculture (Foster and Rosenzweig, 1995).

${ }^{3}$ In contrast, Dranove et al. (2002) show that incomplete report cards can lower welfare by creating adverse selection incentives.
} 
Starting in the mid-1990s, the demand for information has given rise to a burgeoning industry to measure and report health plan performance to consumers. Our analysis is based on a natural experiment in which the General Motors Corporation (GM) started providing formal ratings of health maintenance organization (HMO) managed care health plans to its salaried employees for the 1997 open enrollment period. GM has been at the forefront of creating and disseminating measures of health plan performance and was one of the first companies to provide health plan performance information directly to eligible consumers. For each offered HMO health plan, the ratings listed the performance in a variety of dimensions as being one of three levels: superior, average, and below expected performance. Ratings were not provided for traditional fee for service (FFS) plans or preferred provider organizations (PPOs), since the data used to construct the ratings were only available for HMOs.

We observe enrollment information for all GM salaried employees for 1996 and 1997. As GM is national in scope, our data set contains a large sample of health plans across many markets. In our model, each employee makes a discrete choice from one of the offered health plans in order to maximize her expected utility. The expected utility from a given health plan is a function of plan price, benefits, perceived quality, and idiosyncratic unobserved components. Perceived quality in 1996 is determined solely by prior reputation. The learning model implies that the 1997 posterior perceived quality is a weighted sum of the prior reputation and the signal of plan quality derived from the report card information. We allow for plan-geographic areacoverage tier fixed effects, which can be interpreted as prior reputation fixed effects within the context of the learning model. Because we allow for fixed effects, the estimation identifies the impact of ratings by the extent to which the release of information caused people to switch towards highly rated plans. 
Our Bayesian learning model is similar to a simple fixed effects discrete choice specification where the report card ratings directly enter into the utility function in 1997. However, there are two key differences. First, as the fixed effects reflect prior reputation, the model implies that the posteriors are a weighted average of these effects and the information in the signal, where the weight is determined by the relative precision of the report card signal to the prior. We estimate the weight as a parameter and, for robustness, examine a standard fixed effects model where the magnitude of the fixed effects does not change between the two periods. Second, measuring the value of information is different from measuring the value of a standard product attribute, such as gas mileage for automobiles. Information is valuable largely because it causes consumers to switch health plans, implying that a bad rating may be as valuable as a good rating. In contrast, lower gas mileage is never valuable, and a higher gas mileage will benefit consumers even if they did not switch automobiles. This difference does not change the estimation procedure but, relative to common hedonic models used to assess value, it does imply that a different approach is needed to assess the value of information given the estimated parameters.

We estimate the parameters of our model using simulated maximum likelihood. The results of our estimation indicate a significant effect of the information on choice, suggesting that markets for managed care plans do not reflect complete information. We estimate that the willingness to pay for a plan increases $\$ 267$ per year if one out of six ratings of the plan were average as opposed to below average. In addition, employees seem more sensitive to negative information than positive information. This is consistent with a wide body of work on framing in decision-making and consistent with laboratory experiments investigating the role of information in health plan choice (Hibbard et al. 2000). 
In spite of these relatively high willingness-to-pay figures, we estimate that the information only caused about $3 \%$ of people to switch plans and resulted in a net increase in HMO market share of less than $1 \%$. Indeed, even if every plan had received the most favorable rating, we estimate that HMO market share would have increased by a little less $5 \%$. Thus, even though superior and average ratings significantly increase the posterior utility of most plans, this increase was most often less than the differences in prior utility levels across plans. Corresponding to these relatively small numbers, we estimate that the value created by the report card information is a moderate $\$ 10$ per GM employee per year.

Lastly, based on our estimates of the precision of priors and signal, we conclude that the ratings are noisy signals of quality. The precision of the signal is only about $5 \%$ more than that of the priors. The impact and value of ratings could be greater if they were perceived as less noisy signals of quality.

The remainder of this paper proceeds as follows. Section 2 specifies the learning model, identification, and estimation procedure. Section 3 details the natural experiment and data. Section 4 provides results. Section 5 concludes.

\section{Model and Estimation}

\section{Model}

We consider a simple Bayesian learning model where individual i resides in market $\mathrm{m}$ at time period $\mathrm{t}$, and must choose among a set of plans $\mathrm{j}$. Individuals care about the perceived plan

\footnotetext{
${ }^{4}$ Our plan choice model builds on a number of recent papers that have estimated the impact of price (though not quality) on the choice of health plans (Buchmueller and Feldstein, 1997; Cutler and Reber, 1996; Royalty and Solomon, 1999).
} 
quality, $\mathrm{q}_{\mathrm{j}}$, which is expressed in utility units. Thus, the expected utility function for an individual at time $\mathrm{t}$ is given by:

$$
\mathrm{u}_{\mathrm{ijmt}}=\mathrm{E}_{\mathrm{imt}}\left[\mathrm{q}_{\mathrm{j}}\right]-\alpha \mathrm{P}_{\mathrm{jmt}}+\sigma_{\varepsilon} \varepsilon_{\mathrm{ijmt}},
$$

where $\mathrm{E}$ is a conditional expectation given the available information, $\mathrm{P}$ is price, $\alpha$ and $\sigma_{\varepsilon}$ are parameters, and $\varepsilon$ is a component of utility that is not systematically related to plan quality and is unobservable to the econometrician. ${ }^{5}$ We let the unobservable $\varepsilon_{\mathrm{ijmt}}$ be distributed with a Type I extreme value distribution as this is the distribution that leads to logit shares.

In some specifications, we allow for correlated $\varepsilon$ 's for plans of the same type, using the nested logit specification of Cardell (1997) and Berry (1994). Following these papers, we let

$$
\varepsilon_{\mathrm{ijmt}}=\varepsilon_{\mathrm{ig}(\mathrm{j}) \mathrm{mt}}^{\prime}+\lambda \varepsilon_{\mathrm{ijmt}}^{\prime \prime},
$$

where $\varepsilon^{\prime}$ and $\varepsilon^{\prime \prime}$ are independent, $\lambda$ is a parameter to estimate, $g(j)$ indexes the plan type of plan $\mathrm{j}$ (i.e. HMO, PPO, or FFS), $\varepsilon^{\prime \prime}$ is distributed extreme value, and $\varepsilon^{\prime} \sim \mathrm{C}(\lambda)$, defined as the unique distribution that makes $\varepsilon$ extreme value given $\lambda$ and the distribution of $\varepsilon^{\prime \prime}$. If $\lambda=1$, then the model will be identical to the logit model and the unobservables will be iid, while if $\lambda=0$, the unobservables will be perfectly correlated within a group. The nested logit model is very useful because it provides a natural way to quantify the extent to which consumers are willing to switch between types of plans, and for our purposes it is important to understand the extent to which ratings cause consumers to switch between HMOs and non-HMOs.

\footnotetext{
${ }^{5}$ Although consumers may learn about plan quality from experiences while enrolled in the plan, we assume there is sufficient noise in the learning process that consumers do not consider the value of learning when choosing a health plan. With this assumption, consumers will choose the health plans that maximize their current expected utilities (1), and we do not have to consider strategies in which consumers sample plans in a dynamic context. Because we do not believe that "sampling" plans is a common strategy, we do not consider this assumption particularly restrictive.
} 
We consider individuals at two time periods, 0 and 1 . Signals, in the form of health plan report cards, are given to individuals immediately before they make their choice of health plan at time 1 . Thus, the conditional distribution of quality at time 0 (i.e., the prior) is a function solely of reputation, while the conditional distribution of quality at time 1 (i.e., the posterior) is a function of both reputation and the signal. For analytic ease, we assume that the priors and signals are normally distributed. We let the prior, $\mathrm{q}_{\mathrm{ijm}, 0}$, be distributed

$$
\mathrm{q}_{\mathrm{ijm}, 0} \sim \mathrm{N}\left(\overline{\mathrm{q}}_{\mathrm{jm}}, \mathrm{h}_{1}^{-1}\right),
$$

and let the signal derived from the quality report card be distributed around the true perceived quality as:

$$
\mathrm{s}_{\mathrm{ijm}} \sim \mathrm{N}\left(\mathrm{q}_{\mathrm{j}}, \mathrm{h}_{2}^{-1}\right),
$$

where $h_{1}$ and $h_{2}$ are precisions of the priors and signal respectively. We assume that the priors and signals are uncorrelated across plans in a market. We let the signal $s_{\mathrm{ijm}}$ be related to the published ratings $r_{\mathrm{j}}$, as

$$
s_{\mathrm{ijm}}=\beta r_{\mathrm{j}}+\sigma_{\mathrm{v}} v_{\mathrm{ijm}},
$$

where $\beta$ and $\sigma_{v}$ are parameters and $v_{\mathrm{ijm}} \sim \mathrm{N}(0,1)$ captures time-varying plan level traits that might relate to perceived quality and are observed to the individuals but not to the econometrician. This variable captures factors such as changing provider networks or positive media coverage. We note that the assumption that the signal is normally distributed is an approximation. In reality, the signals will have some complex distribution, based on the distribution of the $r_{j}$ 's conditional on true quality. However, we think that any bias from the normal approximation will be small. 
Given this specification, we can derive the conditional expectation of quality at time 0

and 1. From (3) the prior mean is $\mathrm{E}_{\mathrm{im} 0}\left[\mathrm{q}_{\mathrm{j}}\right]=\overline{\mathrm{q}}_{\mathrm{jm}}$. Using (3) -5$]$ in conjunction with standard Bayesian updating formulas, we obtain a posterior mean of

$$
E_{i m 1}\left[q_{j}\right]=\frac{h_{1} \bar{q}_{j m}+h_{2}\left(\beta r_{j}+\sigma_{v} v_{i j m}\right)}{h_{1}+h_{2}} .
$$

For our estimation process, we estimate each prior mean on quality, $\overline{\mathrm{q}}_{\mathrm{jm}}$, as a separate parameter. We choose this specification because, in keeping with the natural experiment, we want to identify the effect of the ratings separately from any prior on plan quality. Moreover, these parameters may differ across markets for the same plan because of the local nature of physician and hospital networks.

\section{Identification}

Although we have fully specified the model, we have not yet discussed identification. As with discrete choice utility models, we can identify the coefficients only up to a factor of proportionality. Thus, we normalize $\sigma_{\varepsilon}=1$. Similarly, we need to normalize one plan to have prior quality 0 for every market. We normalize one FFS option, the fee-for-service enhanced (FSSE) plan, to have prior mean quality 0 , and call it plan 0 , the reference plan, so that $\mathrm{q}_{0}=0$. Thus, the prior mean qualities for all other plans as well as the signals for all HMOs, should be thought of as relative to the reference plan.

We choose FFSE as the reference plan for two reasons. First, it does not have published ratings. This is important, because if we had chosen an HMO as a reference plan, we would have had to modify the derivation of the posterior in (6) to account for the fact that the posterior 
quality is relative to this reference plan. Second, this plan is homogeneous and offered in every market. This is similarly important because it allows us to compare perceived quality levels across markets, since they will all be relative to the same plan. We could have also chosen FFSB as the reference plan for the same reasons.

There is also another identification issue that is particular to learning models: we cannot jointly identify the precisions, $h_{1}$ and $h_{2}$. The reason for this, which can be seen from examining 6). is that multiplying $h_{1}$ and $h_{2}$ by the same constant would yield the same posterior on quality and not change the prior. Thus, we estimate only the ratio of $h_{1}$ to the sum of $h_{1}$ and $h_{2}$.

Given this normalization, our model becomes:

$$
\begin{aligned}
& \mathrm{u}_{\mathrm{ijmt}, \mathrm{j} \neq 0}=\overline{\mathrm{q}}_{\mathrm{jm}}-\alpha \mathrm{P}_{\mathrm{jmt}}+\varepsilon_{\mathrm{ijmt}} \text {, if } \mathrm{t}=0 \text { or } \mathrm{j} \text { is not an HMO } \\
& \mathrm{u}_{\mathrm{ijmt}, \mathrm{j}=0}=-\alpha \mathrm{P}_{0 \mathrm{mt}}+\varepsilon_{\mathrm{i} 0 \mathrm{mt}}, \quad \text {, } \\
& \mathrm{u}_{\mathrm{ijm} 1}=\tilde{\mathrm{h}} \overline{\mathrm{q}}_{\mathrm{jm}}+\tilde{\beta} \mathrm{r}_{\mathrm{j}}+\tilde{\sigma}_{v} v_{\mathrm{ijm}}-\alpha \mathrm{P}_{\mathrm{jm} 1}+\varepsilon_{\mathrm{ijm} 1} \text {, if } \mathrm{j} \text { is an HMO } \\
& \text { where } \tilde{h}=\frac{h_{1}}{h_{1}+h_{2}}, \tilde{\beta}=\frac{\beta h_{2}}{h_{1}+h_{2}} \text {, and } \tilde{\sigma}_{v}=\frac{\sigma_{v} h_{2}}{h_{1}+h_{2}} \text {. }
\end{aligned}
$$

Note that (7) differs from a standard fixed effects logit model only by the inclusion of one parameter, $\tilde{\mathrm{h}}$.

The prior mean fixed effect parameters $\bar{q}$ in (7) will be identified based on the popularity of plans. Since we include a fixed effect for the prior mean quality of each plan in each market, the price coefficient is identified by the extent to which changes in plan market share are related to changes in prices.

The relative magnitude of the ratings coefficients is identified based on whether there are systematic differences between 1996 and 1997 in the changes in HMO enrollment across markets based on the ratings of plans in those markets. The geographic variation that arises

\footnotetext{
${ }^{6}$ There are two FFS options, the other one being fee-for-service basic (FFSB).
} 
because employees are located in many distinct markets means that we observe many "miniexperiments." This diminishes the influence of unobservable plan traits that would more strongly influence the results if we observed only one market with a limited number of plans.

The absolute scale of the ratings coefficients is identified based on the net number of people switching to HMOs from non-HMO plans between 1996 and 1997. This identification, which is potentially problematic if there is a general trend towards HMO enrollment, is discussed further below.

The learning parameter $\tilde{\mathrm{h}}$ will be identified based on how strongly the period 0 priors enter into the period 1 choices, and how these vary based on the difference between the priors and ratings. The standard deviation parameter $\tilde{\sigma}_{v}$ will be identified based on whether period 1 exhibits a strong added variance in the choice probabilities for HMOs.

In the nested logit model, there is one additional parameter, the correlation parameter, $\lambda$. In the context of a fixed effects model, this parameter will be identified from changes in the attributes of the choices over time within a market. To illustrate, consider a hypothetical market where the price of one HMO rose between 1996 and 1997 and all other attributes of the market remained the same. A high $\lambda$ would imply that the market shares of the non-HMOs and the other HMOs all rose equally in proportion to their 1996 share, while a low $\lambda$ would imply that the market shares of the other HMOs increased at a higher rate than did the market shares of the nonHMOs.

\section{Sensitivity and robustness}

Although the model is well-identified as specified, there are some potentially confounding explanations in the data. Foremost among these is the possibility that changes 
besides the ratings explain the difference in GM HMO enrollment between 1996 and 1997. In particular, aggregate U.S. HMO enrollment was increasing at a rapid rate over our study period, probably in part because of initiatives at other employers and greater familiarity with and acceptance of HMOs. Although we control for initiatives at GM, we are concerned that increased familiarity and acceptance may have caused some of the observed 2.8 percentage point increase in GM HMO enrollment. If present, failing to account for the increased familiarity and acceptance would inflate the absolute scale of the ratings coefficients and of our estimated value of information.

To account for changes in familiarity and acceptance over time, we would ideally want to allow for time-plan type interactions in the utility model (7). To formalize, define these interactions as $\delta_{p(j), t}$, where $p(j)$ indexes the plan type (FFSB, FFSE, PPO and HMO). Without loss of generality, we normalize the $\delta$ 's for period 0 and for FFSE to be 0 , which leaves us with 3 remaining parameters, $\delta_{\mathrm{HMO}, 1}, \delta_{\mathrm{PPO}, 1}$ and $\delta_{\mathrm{FFSB}, 1}$.

We can then add these terms to (7) for period 1, so that our model changes to:

$$
\begin{aligned}
& \mathrm{u}_{\mathrm{ijm} 1, \mathrm{j} \neq 0}=\overline{\mathrm{q}}_{\mathrm{jm}}-\alpha \mathrm{P}_{\mathrm{jmt}}+\delta_{\mathrm{p}(\mathrm{j}), 1}+\varepsilon_{\mathrm{ijmt}}, \text { if } \mathrm{j} \text { is not an HMO } \\
& \mathrm{u}_{\mathrm{ijm} 1}=\tilde{\mathrm{h}} \overline{\mathrm{q}}_{\mathrm{jm}}+\tilde{\beta} \mathrm{r}_{\mathrm{j}}+\tilde{\sigma}_{v} v_{\mathrm{ijm}}-\alpha \mathrm{P}_{\mathrm{jm} 1}+\delta_{\mathrm{HMO}, 1}+\varepsilon_{\mathrm{ijm} 1} \text {, if } \mathrm{j} \text { is an HMO. }
\end{aligned}
$$

The $\delta_{\mathrm{PPO}, 1}$ and $\delta_{\mathrm{FFSB}, 1}$ terms in (8) can be identified from our data, and hence we include them in our estimation. However, since every employee received ratings in $1997, \delta_{\mathrm{HмO}, 1}$ is perfectly collinear with the absolute scale of the ratings, and hence cannot be included as a separate parameter.

\footnotetext{
${ }^{7}$ InterStudy $(1996,1997)$ reports that the number of pure HMO enrollees in the U.S. increased from 52.5 million to 58.8 million people during 1996.
} 
We thus examine three different normalizations for $\delta_{\text {нмо,1 }}$. In our base results (Normalization 1), we set $\delta_{\text {нмо,1 }}=0$, and ignore any trend towards HMOs. For Normalization 2, we use the enrollment patterns for salaried employees at a similar Midwest-based Fortune 50 manufacturing company that did not distribute ratings as a control group. That firm experienced an increase in $\mathrm{HMO}$ enrollment of 1.99 percentage points (from $40.78 \%$ to $42.77 \%$ ) among its salaried employees between 1996 and 1997. Thus, for Normalization 2, we select $\delta_{\text {нмо,1 }}$ to be the value that would have caused a 1.99 percentage point increase in GM HMO enrollment between 1996 and 1997 in the absence of ratings or any price or sample change.

Normalization 3 uses unionized employees at GM as a control group, since these employees were not provided with health plan report cards. The advantage of this normalization, relative to Normalization 2, is that the union workers had the same plan options as the salaried workers. However, during our study period new unionized employees at GM (of which there were relatively few) were required to join an HMO for their first two years of employment. Moreover, union workers may have different preferences than salaried workers, and there may have been some spillover of information from salaried to union workers. HMO enrollment among GM unionized employees increased by 2.8 percentage points between 1996 and 1997 (from $28.0 \%$ to $30.8 \%$ ). We believe these three normalizations span realistic values for trends to HMOs and that Normalization 2 is probably the most accurate.

Given the importance of time-plan type interactions in explaining the absolute magnitude of the coefficients, one might expect that plan type dummies might also play a role. However, this is not the case. We can show that plan type dummies are perfectly collinear with the prior quality means and ratings, and that alternate values of plan type dummies do not affect our substantive conclusions on willingness to pay or switching behavior. 
Moreover, while the normalization of $\delta_{\mathrm{HMO}, 1}$ will affect the estimated switching behavior and the value of information, it will not affect the relative magnitude of the ratings coefficients. Thus, for instance, if we estimate that the increase in expected utility from having a plan be given rating $\mathrm{B}$ instead of rating $\mathrm{A}$ is worth $\$ 100$, this figure will not change with the different normalizations. The fundamental reason for this is that our data allows the specification to identify, without normalization, how much individuals are willing to pay for a plan with a given set of ratings, relative to other ratings.

Another concern is that individuals may have shifted towards highly rated HMOs even in

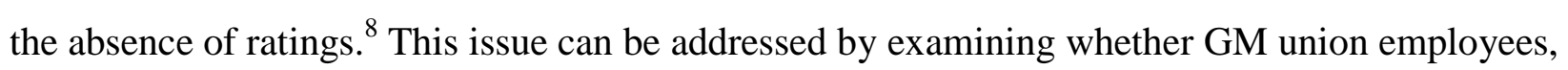
who did not receive ratings, shifted towards highly rated plans. Scanlon et al. (2002) found that using coarser measures of GM union workers' enrollment at the plan level as a control group yielded virtually no difference in the results.

Lastly, one may postulate that the effects of report cards vary within sub-populations of employees. For example, less healthy individuals may be more sensitive to information because they may care more about the ratings or they may be less sensitive to ratings because they may have more prior knowledge. Preliminary analysis using age and number of dependents to proxy for health status did not indicate any substantive distinctions along these dimensions. Similarly, newly hired employees may be more sensitive to ratings information because they may have less prior knowledge. Estimates from a model with only new hires are qualitatively very similar to

\footnotetext{
${ }^{8}$ Since the ratings were constructed from 1995 data, such shifts would have to come from learning about plans from 1996 experience and not from plan responses to ratings.
} 
our base results, although some coefficients are not statistically significant because of the smaller sample size. ${ }^{-}$Hence, we also do not include results from these specifications.

\section{Estimation}

We estimate the parameters of the base specification of (7) using a simulated maximum likelihood estimation procedure. Each enrollee at each time period constitutes one observation. The likelihood for the observation is the probability that the chosen plan was selected, given the parameter vector.

To define the likelihood, let $\mathrm{y}_{\mathrm{imt}}$ denote the chosen plan for individual $\mathrm{i}$ in market $\mathrm{m}$ at time t. Additionally, for ease of notation, group all the parameters in $\theta$, so that $\theta=\left(\overline{\mathrm{q}}_{\mathrm{j}, \mathrm{m}} \forall \mathrm{j}, \mathrm{m}, \tilde{\mathrm{h}}, \tilde{\beta}, \tilde{\sigma}_{\mathrm{v}}, \alpha, \lambda, \delta_{\mathrm{PPO}, 1}, \delta_{\mathrm{FFSB}, 1}\right),{ }^{1}$ and all the exogenous variables in $\mathrm{x}$ so that $\mathrm{x}$ includes the ratings, prices, and identities of all offered plans in each market. Then, the $\log$ likelihood for an individual i satisfies:

$$
\ln \mathrm{L}(\theta \mid \mathrm{y}, \mathrm{x})=\sum_{\mathrm{i}, \mathrm{m}, \mathrm{t}} \ln \left(\frac{1}{\mathrm{NS}} \sum_{\mathrm{s}} \operatorname{Pr}\left(\text { Choice for enrollee } \mathrm{i}, \mathrm{m}, \mathrm{t} \text { is } \mathrm{y}_{\mathrm{imt}} \mid \mathrm{x}, \theta, \mathrm{v}_{\mathrm{ijms}}\right)\right)
$$

where NS is the number of simulation draws per individual (set to 20 for our results), $v_{\mathrm{ijms}}$ is one simulation draw, and the probability of the observed choices are calculated using the logit or nested logit models as appropriate. See Berry (1994) for a derivation of these choice probabilities.

\footnotetext{
${ }^{9}$ Sorensen (2001) finds that new employees learn about plan attributes from social interactions with existing employees. Our findings on new hires suggests that social learning at GM was relatively complete, resulting in similar priors for plans within a market.

${ }^{10}$ Note that $\lambda$ is a parameter only for the nested logit model.

11 The conclusions were insensitive to estimates computed with 40 draws.
} 


\section{Data}

The set of health insurance plans from which employees could choose, as well as the prices employees were charged for each plan, was determined by GM and this set was almost entirely the same before and after the release of the report card. In both periods, all employees had the FFSE and FFSB option, while HMO and PPO options depended on the employees' zipcode of residence. The employees paid for the health plans using 'flex dollars' that could be allocated across several benefit categories (e.g., health insurance, life insurance, disability insurance, and dental insurance), as well as out-of-pocket pre-tax dollars. The price for every health plan was at least as high as the amount of flexible benefit dollars received, which implies that the marginal contribution for health coverage came from out-of-pocket expenses. 12

\section{Variable construction}

The key variables in this analysis are the ratings variables and the price charged to GM workers. HMOs were rated below expected performance, average performance, or superior performance along six domains, labeled by GM as operational performance, preventive health care services, medical and surgical care, women's health issues, access to care, and patient satisfaction. The performance ratings were based on aggregated data from the Health Plan Employer Data and Information Set (HEDIS) and site visits to the HMOs [Scanlon et al. (2002)]. Because HEDIS data were only available for HMOs, no performance ratings were released for traditional FFS or PPO plans. The underlying HEDIS data typically relate to rates of utilization of selected services, survey responses regarding satisfaction, and various aspects of the provider group and measures of access. Outcome measures were generally not included in these early 
report cards and case mix adjustments were crude at best. Details regarding the variables and construction of the report card ratings are reported in Scanlon et al. (2002).

During the open enrollment period for 1997, non-union GM employees were given an information sheet for each of the HMOs from which they could choose. The information sheet designated each plan as 1, 2, or 3 diamonds for each domain to represent the plan ratings. An example is provided in Figure 1, though no employee received the exact sheet represented in Figure 1 because no employees were offered the exact set of plans displayed.

In some cases for HMOs in 1997, plans were given a rating of "missing" for some domains because of insufficient data from the plans. Employees were informed that these plans did not provide sufficient information. We treat a missing rating differently from no rating; note that all plans in 1996 and all non-HMO plans in 1997 have no rating. The reason is that a missing rating conveys information while no rating does not convey information. Hence, consumers may update their posterior quality based on a missing rating, but not if there is no rating.

Although there are six domains of performance, they are correlated and earlier work suggested we could not identify independent effects of ratings by domain of performance. Thus for each plan we create summary measures of quality based on the number of ratings that are superior, average, below average, or missing (see Table 1). Apart from being an econometric convenience, such aggregation might be useful because individuals may not be able to process information from all the domains. They may adopt simplifying decision rules such as selecting plans with the most superior ratings or fewest below average ratings (Hibbard et al., 1997). Existing work from laboratory settings is consistent with such decision rules (Hibbard et al.,

\footnotetext{
${ }^{12}$ In both years the amount of flex dollars provided by GM was equivalent to the price for FFSB in each coverage category.
} 
2000). In addition to these variables, we also include a dummy variable that indicates whether a plan was accredited.

We treat the ratings as exogenous, for two reasons. First, the new information was provided only to salaried GM workers who generally form a small subset of the enrollment base for any given health plan. Second, the information, which was released in 1997, is based on 1995 plan performance, when most plans would not have anticipated the construction and release of the report card.

We define price as the difference between the annual out-of-pocket price and the allotted flex dollars. 13 Importantly, we treat prices as exogenous. The assumption of exogenous prices reflects the institutional details in conjunction with the short time window surrounding the experiment that we analyze. The prices we observe are based on out-of-pocket costs charged to employees. We do not observe premiums charged to GM, which one would expect to be endogenous in a market setting, varying positively with quality. In contrast, out-of-pocket prices were set by GM. In our estimation, we will control for plan fixed effects. Thus, any endogeneity in these prices must arise from GM changing the out-of-pocket prices in response to changes in some unobserved attribute of the plan from 1996 to 1997. Conversations with GM suggest that this is a very unlikely source of price variation. Instead, changes in prices between 1996 and 1997 were largely chosen to be correlated with the observed quality measures, in order to steer employees to high quality plans. 14

Since the price coefficients in our models are identified by changes in plan out-of-pocket premiums over time, we reported this statistic (Table 1). One can see that the mean out-of-pocket

\footnotetext{
${ }^{13}$ The flex dollar amount varies from $\$ 1764$ for employee coverage to $\$ 4812$ for family coverage. It does not change between 1996 and 1997.
} 
prices for plans stayed relatively constant from 1996 to 1997, although there is substantial variation in prices over time for the same plan, reflected in a standard deviation of $\$ 436$ on the change in price for family coverage.

\section{Sample}

The firm covered over 1.6 million active employees, retirees, and dependents. The analysis is based on the health plan choices over two years of the approximately 70,000 active, salaried employees based in the U.S. (Table 2) ${ }^{1-15}$ The set of health plans offered was very stable during the study period. We dropped from the analysis the 175 employees who were enrolled in one of five plans (three HMOs and two PPOs) that were offered in only one of the two years.

Employees could choose from four different coverage categories: single, employee and spouse, employee and children, and employee and family. The most popular coverage category is employee and family, while employee and spouse is second (Table 2). Coverage category could affect plan preferences in a variety of ways. For example, employees with children may be more interested in the set of available pediatricians and plan performance in the area of pediatric care.

In addition to the coverage category, employees could choose from a menu of different plans that depended on their zip code of residence. About $36.6 \%$ of employees chose HMOs in 1996, a number that rises to 39.4\% in 1997 (Table 2). In 1997, HMOs were the most popular type of plan for employees with children, while FFS plans dominated for employees without children.

\footnotetext{
${ }^{14}$ Though positive, the collinearity between out-of-pocket prices and ratings is sufficiently small to allow for identification even with a more richly parameterized functional form for the effect of price on utility. Moreover, a richer functional form does not substantively affect the conclusions (Scanlon et al., 2002).

${ }^{15}$ Dependents were not analyzed separately because they almost always made the same choice as the employee with GM coverage eligibility. Retirees were excluded because they are frequently Medicare-eligible, making the nature of plan choice different than for the non-Medicare population. Individuals with missing or obviously incorrect zip
} 
More than 90\% of employees chose the same plan in 1996 and 1997 (Table 3). Given that the total number of employees who switched plans between 1996 and 1997 was less than 10\%, the impact of the ratings on plan switching is, at most, moderate. Among the employees who switched plans, employees who switched from an HMO were somewhat more likely to choose an HMO than were employees who switched from a PPO or FFS plan. The fact that employees most often do not switch the type of health plan that they choose is likely to mean that the estimation will reject a simple logit specification in favor of a nested logit.

For our analysis, employees are assigned to geographic areas based on the set of HMO and PPO health plans from which they could choose. All employees who share a common set of plan choices are grouped into the same geographic area. Geographic areas are mutually exclusive, but plans may serve multiple geographic areas. For example, plan A could be offered in San Francisco and south to Santa Cruz, and plan B could be offered in San Francisco and north through Marin County. This would result in three areas. Area 1 would represent Santa Cruz, with only plan A offered. Area 2 would represent Marin County, with only plan B offered. Area 3 would be San Francisco, with both plans offered.

For our analysis we define a "market" as a particular geographic area/coverage category combination. We exclude plans that had zero enrollments in a market for either year. In most cases, this would occur when the plan was not a realistic choice for the employees in that market, largely due to geographic location. After excluding markets with fewer than 5 employees or only 1 plan, we have observations on 132 plans, including 106 HMOs, 24 PPOs and 2 FFS plans, spread across 525 geographic area/coverage markets. Table 4 documents descriptive statistics by markets. On average, markets have 3.83 plans $($ minimum $=2$, maximum $=9$ ). In 1996, the mean

code information also were omitted from the analysis. Union employees were not included because they were not given the report card data and we lacked detailed data about enrollment for union members. 
number of employees per cell was 133 (minimum $=5$, maximum $=8246$ ). In 1997, the cells were slightly smaller $($ mean $=130$, minimum $=5$, maximum $=7996)$.

\section{Results}

In this section, we detail the estimates of the model developed in Section 2. We then use the model, together with the estimated coefficients, to examine the implications of our estimates on consumer behavior, valuations, and beliefs in the context of our Bayesian learning model.

\section{Coefficient estimates}

In Table 5, we provide the simulated maximum likelihood estimates of the model specified in (7) with the base normalization of $\delta_{\mathrm{HMO}, 1}=0$. We provide the results from logit and nested logit specifications. The logit is equivalent to the nested logit model where the parameter $\lambda$ (from (2) is constrained to be 1 , so that there is no correlation between the unobservables for plans within a group. In addition, we also estimate a nested logit fixed effects model as a further check on the robustness of our parameter estimates. This fixed effects model is our base model with the constraint that $\tilde{\mathrm{h}}=1$.

The results are qualitatively similar between the different specifications. The coefficients on the fixed effects model are particularly similar to the nested logit learning model. For instance, the "average quality" coefficients are virtually identical, and the price coefficients vary only between -0.264 and -0.269 .

\footnotetext{
${ }^{16}$ This specification is also consistent with a learning model where consumers have identical zero-mean priors about plan quality and where the $\overline{\mathrm{q}}$ 's pertain to plan attributes other than quality.
} 
All four ratings on quality are significantly different from 0 . While "below average quality" and "missing data" are negative, "average quality" and "superior quality" are positive. There is no statistical difference between the effects of average and superior ratings, nor between missing and below average. We return to the magnitudes implied by these coefficients below. The coefficient on "accredited" is negative, but only statistically significant in the logit model. In all models, the time interaction for FFSB, $\delta_{\mathrm{FFSB}, 1}$, is negative and statistically significant, while the corresponding PPO interaction, $\delta_{\mathrm{PPO}, 1}$, is insignificant and very close to 0 . The standard deviation of the random effect, $\tilde{\sigma}_{v}$, is estimated to be insignificant and small in magnitude relative to the ratings for all the models.

For the specifications which allow learning, the prior weight $\tilde{h}$ is estimated to be about 0.95 and significantly different from both 0 and 1 . Using the definition of $\tilde{\mathrm{h}}$ in (7) this implies that the posterior precision of plan quality is only 5.3\% higher than the prior precision. This suggests that, even in the presence of ratings, consumers are not fully informed.

In the nested logit model, the correlation parameter $\lambda$ is estimated to be 0.561 , and is significantly different from both 0 and 1 . This suggests that we can reject the logit model because there are idiosyncratic preferences within plan types. Because of this result, we emphasize the nested logit results in the discussion that follows.

We find that the coefficient on price is significantly negative. Although our primary concern is not to estimate the effect of price on health plan choice, understanding the estimated magnitude of our price coefficient is very important, since our estimates of the value of information will ultimately depend on this magnitude. The standard way to evaluate the magnitude of a price coefficient is to evaluate the elasticity of demand that it implies. However,

\footnotetext{
${ }^{17}$ Wedig and Tai-Seale (2001) also find a response to information.
} 
it is somewhat problematic to define a price elasticity for health plans, since a large, and in our case unknown, portion of the price is paid by the employer. To avoid having to use an arbitrary number for the total price of health coverage, we instead evaluate the semi-elasticity of price, defined to be the average percent change in the probability of choosing a plan given a $\$ 100$ increase in the annual price. We find that the $\$ 100$ increase in price would result in a reduction in plan share of $3.12 \%$ on average across plans. These numbers are very similar to those found in the literature on health plan choice. 18

The models are estimated with 1488 prior mean quality parameters. Instead of listing each parameter value, the mean and standard deviation of the estimated coefficients within each group are summarized at the bottom of Table 5. We find that the magnitudes of the prior quality coefficients are much larger than the magnitudes of the ratings coefficients, which, in combination with the fact that $\tilde{h}$ is close to 1 , suggests that the prior information is much more important than the signal in determining the posterior. Also, HMOs are estimated to have a negative prior quality level (i.e., lower than the FFSE plan), with the 818 prior mean HMO dummies having a mean of -0.251 . This implies that for the majority of plans, average and superior ratings raise expectations about quality relative to the prior. 19

\footnotetext{
${ }^{18}$ Cutler and Reber (1996) find an elasticity of -2 for Harvard employees, which is equivalent to a semi-elasticity of $4 \%$ per $\$ 100$ increase given that the average gross premium is roughly $\$ 5000$ in their study. Royalty and Solomon (1999) report price elasticities of -1 to -1.8 for Stanford employees. Using the midpoint of -1.4 and noting that their average gross premium is roughly $\$ 4000$, this implies a semi-elasticity of 3.5\% per $\$ 100$ price change. Buchmueller and Feldstein (1997) report that an increase in net price from $\$ 120$ to $\$ 240$ reduced plan share by $4 \%$ for University of California employees, and that a further $\$ 120$ increase reduced the plan share by $3 \%$. Scaling these down to $\$ 100$ increments yields semi-elasticities of between $2.5 \%$ and $3.3 \%$ per $\$ 100$ price change. Because they allow a discrete jump in response associated with any positive change in price, Buchmueller and Feldstein (1997) find much larger price elasticities, which we do not replicate, when the price changes from $\$ 0$ to $\$ 120$.

${ }^{19}$ This result is sensitive to assumptions about whether there are plan-type fixed effects apart from quality. Our model assumes that there are not. Yet, plan-type fixed effects might exist, reflecting different benefits and restrictions on care. As discussed in Section 2, the presence of unaccounted plan-type fixed effects would not affect any other conclusion of the model.
} 
Table 6 reports coefficient estimates from the three nested logit normalizations discussed in Section 2, which differ in their values for the HMO time trend $\delta_{\mathrm{HMO}, 1}$. Normalization 1 (the base normalization, also in Table 5) sets $\delta_{\mathrm{HMO}, 1}=0$, while Normalization 2 sets $\delta_{\mathrm{HMO}, 1}=0.101$, chosen to yield a 1.99 percentage point increase in $\mathrm{HMO}$ enrollment with the base coefficients in the absence of price changes or ratings information. Normalization 3 sets $\delta_{\mathrm{HMO}, 1}=0.143$, analogously chosen to yield a 2.8 percentage point increase in HMO enrollment. The collinear relationship between the normalizations implies a specific relationship between the coefficients. In particular, only the ratings coefficients change, and each of the four ratings coefficients change by the same amount.

\section{Impact of ratings on choice}

Table 7 shows the predicted effect of ratings on 1997 plan choices, using the estimates from the nested logit models under the three normalizations given in Table 6. To find these figures, we compute individuals' choices in the absence and presence of ratings information. We

perform the computation by simulating over the unobservables $\varepsilon_{\mathrm{ijmt}}$ and $v_{\mathrm{ijm}}$ for each individual in 1997. When simulating the counterfactual absence of ratings, we assume that the individuals do not update at all and, hence, that their posterior expectation of quality is identical to their prior expectation. We also assume that the unobservables $\varepsilon_{\mathrm{ijmt}}$ and $v_{\mathrm{ijm}}$ do not change with the implementation of ratings.

The first row reports the predicted net changes in market share between 1996 and 1997 assuming no ratings had been released. These are the baseline estimates of what would have happened in the absence of ratings. The 0.21 percentage point increase in HMO market share that is reported for Normalization 1 is due to changes in prices and the set of employees. The 
comparable increase for Normalization 2 is 2.15 percentage points and for Normalization 3 it is 2.97 percentage points. These figures, which are larger because they incorporate the time trend $\delta_{\mathrm{HMO}, 1}$, approximate what happened in the comparable firm or among GM union workers.

Rows 2 through 4 estimate the impact of ratings under several scenarios. In row 2 we assume all plans had average scores on all ratings. Under this scenario, all three normalizations report a 6.60 percentage point increase in HMO market share, which is the highest possible HMO enrollment increase across ratings. Row 3 assumes all of the plans had one "below average" rating and the rest were average, yielding a slightly lower figure. The fourth row estimates the impact given the actual ratings that were released, indicating that all models predict a 2.81 percentage point increase in share from 1996 to 1997 . Note that these values are invariant to the normalization used.

In contrast, Normalizations 2 and 3 predict that a smaller part of the observed increase in HMO market share is attributable to ratings. For instance, under Normalization 1, the release of the actual ratings caused a 2.60 percentage point increase in HMO share, while Normalization 2 reports this figure as a much smaller 0.66 percentage points.

These figures are all modest compared to the 36.6 percent of employees who chose HMOs in 1996. Moreover, under the most believable normalization, Normalization 2, even if every plan had received the most favorable rating, the ratings would have caused only a 4.45 percentage point increase in HMO market share. Thus, these ratings did not cause substantial numbers of people to switch to managed care health plans.

\section{Willingness to pay to avoid plans with below average ratings}


Given our estimates in Table 5, it is straightforward to compute the willingness of individuals to pay for plans with better ratings. This computation can be done by dividing the utility gain by the marginal utility of money, which is $\alpha$, the coefficient on price. Using the nested logit model, the estimates suggest that posterior expected utility increases a significant amount from avoiding "below average quality" or "missing data" ratings: For instance, the increase in posterior utility from a plan if one out of six quality characteristics changes from "below average" to "average" is worth $\$ 1000 \times(0.050-(-0.020)) / 0.264 \approx \$ 267 /$ year. Essentially employees would pay $\$ 267 /$ year to avoid a plan with one extra below average rating. This figure does not change across the different normalizations given in Table 6, but is mildly affected by specification. The estimates for the fixed effects model and the (non-nested) logit model are similar, $\$ 235$ and $\$ 275$, respectively.

\section{Value and impact of ratings}

Measuring the value of information is different from measuring the value of other product attributes, such as gas mileage for automobiles. Information is valuable to the extent that it causes consumers to alter their behavior. Thus, a bad rating may be just as valuable as a good rating, since it will allow a consumer to avoid a given plan. In contrast, assuming that the consumer values gas mileage positively, lower gas mileage is never valuable.

The textbook measure of the value of information is given by DeGroot (1970, p. 197), who considers the case of observing signals with subsequent decisions. To use this measure in our context, define expected utility for a given consumer $U_{\text {imt }}(\mathfrak{I}, j)$ to be a function of the information $\mathfrak{I}$ and the choice $\mathrm{j}$ and let $\mathrm{Y}_{\text {imt }}(\mathfrak{I})$ be the utility maximizing choice given

\footnotetext{
${ }^{20}$ These results are quantitatively similar to Scanlon et al. (2002).
} 
information $\mathfrak{I}$. We can summarize the realized 1997 information as the signals for all plans in the market, $\mathfrak{I}=\mathrm{s}_{\mathrm{i} \bullet \mathrm{m}}$, and the 1996 information as the null set, $\mathfrak{I}=\varnothing$. Defining $\mathrm{f}(\mathrm{s}, \mathrm{q})$ to be the ex ante density of signals and quality, the DeGroot measure is:

$$
\begin{aligned}
& \mathrm{V}=\sum_{\mathrm{m}} \sum_{\mathrm{i}} \iint\left[\mathrm{U}_{\mathrm{im} 1}\left(\mathrm{~s}, \mathrm{Y}_{\mathrm{im} 1}(\mathrm{~s})\right)-\mathrm{U}_{\mathrm{im} 1}\left(\mathrm{~s}, \mathrm{Y}_{\mathrm{im} 1}(\varnothing)\right)\right] \mathrm{f}(\mathrm{q} \mid \mathrm{s}) \mathrm{f}(\mathrm{s}) \mathrm{ds} \mathrm{dq} \\
& =\sum_{\mathrm{m}} \sum_{\mathrm{i}} \int\left[\mathrm{U}_{\mathrm{im} 1}\left(\mathrm{~s}, \mathrm{Y}_{\mathrm{im} 1}(\mathrm{~s})\right)-\mathrm{U}_{\mathrm{im} 1}\left(\mathrm{~s}, \mathrm{Y}_{\mathrm{im} 1}(\varnothing)\right)\right] \mathrm{f}(\mathrm{s}) \mathrm{ds}
\end{aligned}
$$

where the equality follows from the fact that the expected utility and choice depend only on the signal.

As we do not observe the ex ante expectation of the distribution of signals $f(s), 010)$ is not directly computable. However, if we are willing to assume that the ex post distribution of ratings was equal to the ex ante distribution, then we can substitute the actual signal for the distribution of signals given a large set of similar consumers. In this case, we obtain:

$$
\mathrm{V} \approx \mathrm{U}=\sum_{\mathrm{m}} \sum_{\mathrm{i}}\left[\mathrm{U}_{\mathrm{im} 1}\left(\mathrm{~s}_{\mathrm{i} \bullet \mathrm{m}}, \mathrm{Y}_{\mathrm{im} 1}\left(\mathrm{~s}_{\mathrm{i} \bullet \mathrm{m}}\right)\right)-\mathrm{U}_{\mathrm{im} 1}\left(\mathrm{~s}_{\mathrm{i} \bullet \mathrm{m}}, \mathrm{Y}_{\mathrm{im} 1}(\varnothing)\right)\right]
$$

Note that $[11)$ differs from the automobile case in that the second term is $\mathrm{U}_{\mathrm{im} 1}\left(\mathrm{~s}_{\mathrm{i} \bullet \mathrm{m}}, \mathrm{Y}_{\mathrm{im} 1}(\varnothing)\right)$ and not $\mathrm{U}_{\mathrm{iml}}\left(\varnothing, \mathrm{Y}_{\mathrm{iml}}(\varnothing)\right)$. Also, $(11)$ is a direct ex post measure of value for an individual. Interpreting (11) in this way, an individual will only value information if it causes her to change her choice of health plan. Lastly, while (11) is in utility terms, $\mathrm{U} / \alpha$ is the dollar value of the ratings.

Table 8 presents results on the value of the ratings $\mathrm{U} / \alpha$ and the percent of employees who switched plans as a result of the ratings, using the three normalizations from Table 6 . We find that, under Normalization 1, the information was worth an average of \$16 per employee (or 
$\$ 1.08$ million total) per year, and approximately $\$ 10$ under Normalizations 2 and 3.21 The fraction of enrollees who switch plans as a result of the ratings varies from $3.00 \%$ to $4.26 \%$ across the normalizations. While ratings did draw people from non-HMOs to HMOs, this effect was modest: under Normalization 2, $1.23 \%$ of people switched to HMOs as a result of good ratings, but $0.57 \%$ switched away from HMOs as a result of poor ratings.

It might appear puzzling that the estimated $\$ 10$ value of information is so much smaller than the $\$ 267$ willingness to pay to change just one out of six ratings from below average to average. The reason for this disparity is that the quality priors are much larger than the price or ratings coefficients, and hence only a small fraction of the employees switched plans as a result of the ratings. Thus, even though the above signal change is worth $\$ 267$, most people would not switch plans just because of a $\$ 267$ change in utility. For the $97 \%$ of enrollees who did not switch plans as a result of the ratings, the ratings had no ex post value.

The estimates of the value of information are derived directly from our model and are based on revealed preferences. They do not reflect several potentially important issues related to the value of information. If consumer responses reflect a misperception about what the ratings measure, as opposed to a rational response to new data, the value of information estimates would not reflect the true value. Similarly, our definition of value assumes that information only provides value through the ability to change enrollment patterns. A consumer who does not switch plans gains no utility from learning that her plan is superior and loses no utility from

\footnotetext{
${ }^{21}$ The results are consistent with Mennemeyer et al. (1997) who find a small response to ratings.

${ }^{22}$ Recall that we define switching behavior based on 1997 behavior, holding the unobservables fixed. Our model overpredicts the percent of people switching between 1996 and 1997 since we do not use this information in our estimation. For robustness, we also estimated models with person-plan random effects. These models fit the percent of people who switch plans between 1996 and 1997 much better but otherwise give similar results. For instance, using Normalization 2 and a random effects logit model, we find that ratings cause $2.83 \%$ of employees to switch plans resulting in a per-capita value of information of $\$ 8$. However, given the similarity of the results, and that our focus is on predicting switching behavior as a result of the ratings, we do not focus on the random effects model any further.
} 
learning that her plan is below average, though one could certainly argue that such effects should be considered in the calculations.

Though our measures of value are incomplete, the question arises as to whether they are large or small. The estimated value of information is a small fraction of the cost of health plans. One could also compare the estimates to the costs of generating the information. Such estimates are difficult to obtain. Wholey et al. (2000) report that the cost for each plan to produce information is $\$ 2.67$ per enrollee, which is much smaller than our estimates of value. However, this does not include the costs to GM of creating and disseminating the report card or the cost to health care providers of collecting the information.

\section{Relationship between prior and signal}

Figure 2 details the relationship between the prior mean on quality and the mean quality signal for all HMOs. The figure plots the prior and signal for each of the 818 HMO observations, as well as a fitted regression line. The mean quality signal is evaluated by setting $v_{\mathrm{ijm}}=0$. These results are invariant across the normalizations in Table 6.

One can see from the figure that there is a distinct, though weak, positive relationship between the prior mean and the mean signal. In particular, we find a 0.14 correlation, as well as a 0.14 Spearman Rank correlation, that are both statistically significant. We draw two broad implications from these results. First, the positive correlation implies that individuals were not completely ignorant of plan traits in the absence of the report card information. ${ }^{23}$ Second, in conjunction with the fact that the posterior precision is not much higher than the prior precision, the relatively low correlation and small response to ratings imply that the ratings are noisy

\footnotetext{
${ }^{23}$ This result has also been found by Luft et al. (1990) and Chernew et al. (1998).
} 
signals of quality. ${ }^{24}$ This is consistent with the fact that the rating construction process has been widely criticized for inaccuracies and imprecision. Moreover, this suggests that better, less noisy ratings would provide a more informative signal and hence be more valuable.

\section{Conclusions}

Economists have long recognized the importance of information in markets. They also realize that mechanisms exist to inform consumers even when there is a lack of formally provided information on product attributes. In spite of this, relatively little literature has examined changes in information structure and their impact on behavior. The health care industry presents an ideal opportunity to address these issues because of the salience of information in this market and the continuing evolution of efforts to provide explicit information on health plan quality.

This paper assesses the impact of the release of information on health plan choices by estimating a Bayesian learning model identified by a natural experiment. We find that information does have an effect on health plan choice. Consumers have a moderately large willingness to pay to avoid plans with bad ratings. However, only about $3 \%$ of people switch plans as a result of the ratings, implying a low, but still positive, per capita value of information. The report cards drew few people in net to managed care plans, although they did cause moderate movements to and from managed care. Even if all HMOs improved to the point where they obtained the most valuable ratings in all categories, we estimate that they would draw less than $5 \%$ of people away from non-HMOs.

\footnotetext{
${ }^{24}$ Hibbard and Jewett (1996); Hibbard et al. (2000); Robinson and Brodie (1997); and Tumlinson et al. (1997) also find that consumers do not feel fully informed as a result of ratings.
} 
The results indicate that despite the existence of informal information-generating mechanisms, formal information is valuable. Our Bayesian learning model allows us to quantify the value and we estimate that employees were willing to pay about $\$ 10$ per year. This relatively modest value reflects the small increase in the estimated precision of perceived quality due to the information release, suggesting that this information was noisy, which is widely considered to be true in the field. Not surprisingly, this implies that better report cards would be more valuable. 


\section{References}

Ackerberg, Daniel A., 2001. "Advertising, Learning and Consumer Choice in Experience Good Markets: An Empirical Examination." Mimeo, UCLA.

Akerlof, George A., 1970. The Market for 'Lemons': Quality Uncertainty and the Market Mechanism. Quarterly Journal of Economics 84: 488-500

Arrow, K., 1963. Uncertainty and the Welfare Economics of Medical Care. The American Economic Review. 53(5). 941-973.

Berry, S.T., 1994. Estimating discrete-choice models of product differentiation. RAND Journal of Economics, 25, 242-262.

Buchmueller, T.C., and P. Feldstein, 1997. The effect of price on switching among health plans. Journal of Health Economics, 16, 231-247.

Cardell, N.S., 1997. "Variance Components Structures for the Extreme-Value and Logistic Distributions with Application to Models of Heterogeneity," Econometric Theory, 13, 185213.

Crawford, Gregory S. and Matthew Shum, 2000. "Uncertainty and Learning in Pharmaceutical Demand." Mimeo, Duke University.

Chernew, M.E., Scanlon, D., and R. Hayward, 1998. "Insurance Type and Choice of Hospital for Coronary Bypass Graft Surgery,” Health Services Research, 33(3) 447-466.

Cutler, D.M., and S. Reber, 1996. Paying for health insurance: the tradeoff between competition and adverse selection. Working paper 5796, National Bureau of Economic Research, Cambridge, MA.

DeGroot, Morris H., 1970. Optimal Statistical Decisions, New York: McGraw-Hill.

Dranove, D., D. Kessler, M. McClellan, M. Satterthwaite. 2002. Is More Information Better? The Effects of 'Report Cards' on Health Care Providers. NBER Working Paper 8697.

Erdem, T. and M. Keane. 1996. "Decision Making Under Uncertainty: Capturing Dynamic Brand Choice Processes in Turbulent Consumer Goods Markets." Marketing Science 15: 120.

Foster, A., and M. Rosenzweig. 1995. Learning by Doing and Learning from Others: Human Capital and Technical Change in Agriculture. Journal of Political Economy, 103, 11761209. 
Hibbard, J.H., L. Harris-Kojetin, P. Mullin, J. Lubalin, and S. Garfinkel. 2000. Increasing the impact of health plan report cards by addressing consumers' concerns. Health Affairs, 19, 138-143.

Hibbard, J.H., and J.J. Jewett. 1996. What type of quality information do consumers want in a health care report card? Medical Care Research and Review, 53, 28-47.

Hibbard, J.H., P. Slovic, and J.J. Jewett. 1997. Informing consumer decisions in health care: implications from decision-making research. Milbank Quarterly, 75, 395-414.

InterStudy $(1996,1997)$. The Competitive Edge. St. Paul, MN: InterStudy Publications.

Irwin, D. and P. Klenow. 1994. Learning-by-Doing Spillovers in the Semiconductor Industry. Journal of Political Economy, 102, 1200-1227.

Jin, Ginger and Phillip Leslie. 2001. "The Effects of Disclosure Regulation: Evidence From Restaurants." Mimeo, UCLA.

Luft, H. S., D. H. Garnick, C. S., Mark, D. H., Peltzman, D.J., Phibbs, C.S., Lichtenberg, E., McPhee, S.J. June 6, 1990. "Does Quality Influence Choice of Hospital?" Journal of The American Medical Association 263(21): 2899-2906.

Mennemeyer ST. Morrisey MA. Howard LZ, 1997. Death and reputation: how consumers acted upon HCFA mortality information. Inquiry. 34:117-28.

Milyo, Jeffrey and Joel Waldfogel, 1999. The Effect of Price Advertising on Prices: Evidence in the Wake of 44 Liquormart. American Economic Review 89: 1081-96.

Robinson, S., and M. Brodie. 1997. Understanding the quality challenge for health consumers: the Kaiser/AHCPR survey. Journal on Quality Improvement, 23, 239-244.

Rothschild, Michael and Joseph E. Stiglitz, 1976. Equilibrium in Competitive Insurance Markets: An Essay on the Economics of Imperfect Information. Quarterly Journal of Economics 90: 630-49.

Royalty, A.B., and N. Solomon. 1999. Health plan choice: price elasticities in a managed competition setting. Journal of Human Resources, 34, 1-41.

Scanlon D.P., Chernew, M.E., McLaughlin, C.G., Solon, G., 2002. "The Impact of Health Plan Report Cards on Managed Care Enrollment," Journal of Health Economics, 21, 19-41.

Sorensen, A. 2001. Social Learning in the Demand for Employer-Sponsored Health Insurance. Mimeo, University of California San Diego. 
Stiglitz, Joseph E. 1989. "Imperfect Information in the Product Market.". In Richard Schmalensee and Robert D. Willig (ed.), Handbook of Industrial Organization: Volume 1, Amsterdam: North-Holland.

Tumlinson, A., H. Bottigheimer, P. Mahoney, E.M. Stone, and A. Hendricks. 1997. Choosing a health plan: what information will consumers use? Health Affairs, 16, 229-238.

Wedig, Gerard J. and Ming Tai-Seale. 2001. "Do Report Cards Improve the Informational Efficiency of the Health Insurance Market? Evidence from the Federal Employees' Health Benefits Plan.” Mimeo, Indiana University.

Wholey, Douglas R., Rema Padman, Richard Hamer and Shawn Schwartz, 2000. "The Diffusion of Information Technology among Health Maintenance Organizations." Health Care Management Review 25, 24-33. 


\section{Figure 1}

\section{Example Information Sheet}

\section{COMPARING YOUR 1997 GM MEDICAL OPTIONS}

The following table shows the rating of the HMO option(s) available in eight selected quality measures. The ratings are based on historical data and therefore may not necessarily represent the quality of care you will receive in the future. GM does not endorse or recommend any particular medical plan option. The medical plan you elect is your personal decision.

For a more complete description of the eight selected quality measures, see the GM Medical Plan Guide.

\begin{tabular}{|c|c|c|c|c|c|c|c|c|}
\hline & $\underset{\text { Aecredit tod? }}{\text { NeOA }}$ & $\begin{array}{l}\text { Benchmark } \\
\text { HAOO? }\end{array}$ & $\begin{array}{c}\text { Opore } \\
\text { tonat } \\
\text { Porromanes }\end{array}$ & $\begin{array}{l}\text { Proventive } \\
\text { Caro }\end{array}$ & $\begin{array}{l}\text { Modical } \\
\text { Surgical } \\
\text { Carp }\end{array}$ & $\begin{array}{l}\text { Wormon's } \\
\text { Hesith }\end{array}$ & $\begin{array}{l}\text { Accosts } \\
\text { to Caro }\end{array}$ & $\begin{array}{l}\text { Pationt } \\
\text { Sotistaction }\end{array}$ \\
\hline $\begin{array}{l}\text { O001 } \\
\text { Basic Medical Plan }\end{array}$ & & Infor & mation Cur & rrently No & Availabl & & & \\
\hline $\begin{array}{l}0002 \\
\text { Enhanced Medical Plan }\end{array}$ & . & Intor & mation Cur & rrently No & t Availabl & & & \\
\hline $\begin{array}{l}\text { PPO } 2190 \\
\text { Blue Preferreo Plus }\end{array}$ & & infor & mation Cur & irently No & t Availabl & & & \\
\hline $\begin{array}{l}\text { HMO } 2101 \\
\text { Care Choices HMO }\end{array}$ & Yes & No & $\boldsymbol{\Lambda}$ & $\boldsymbol{M \Lambda}$ & $\mathbf{M}$ & $\mathbf{M A}$ & $\boldsymbol{\Lambda} \mathbf{\Lambda}$ & $\mathbf{\Lambda A}$ \\
\hline $\begin{array}{l}\text { HMO } 2108 \\
\text { BCN G Lakes SW MI }\end{array}$ & Yes & No & $\mathbf{A}$ & $\boldsymbol{\Delta}$ & $\Delta$ & $\Delta$ & $\Lambda$ & $\mathbf{M}$ \\
\hline $\begin{array}{l}\text { HMO } 2113 \\
\text { BCN Health Central }\end{array}$ & Yes & No & $\boldsymbol{\Lambda}$ & $\boldsymbol{L} \mathbf{A}$ & $\mathbf{A \Lambda}$ & $\mathbf{M A}$ & $\Delta$ & $\Delta$ \\
\hline $\begin{array}{l}\text { HMO } 2116 \\
\text { Priority Health }\end{array}$ & Yes & No & $\boldsymbol{M A}$ & $\Delta$ & $\boldsymbol{A}$ & $\Delta \mathbf{A}$ & $\boldsymbol{\Delta} \mathbf{A} \mathbf{A}$ & $\boldsymbol{M A}$ \\
\hline $\begin{array}{l}\text { HMO } 2117 \\
\text { Care Choices HMO W ML }\end{array}$ & Yes & No & $\Delta \Lambda$ & $\boldsymbol{M A} \mathbf{A}$ & $\Delta \mathbf{A}$ & $\Delta \mathbf{A}$ & $\mathbf{A}$ & $\mathbf{A M A}$ \\
\hline $\begin{array}{l}\text { HMO } 2 \$ 18 \\
\text { BCN West Michigan }\end{array}$ & Yes & No & $\Delta \mathbf{A}$ & $\Delta$ & $\boldsymbol{\Lambda}$ & $\Delta$ & $\boldsymbol{\Lambda}$ & $\mathbf{\Lambda}$ \\
\hline
\end{tabular}

Key: $\mathbf{\Lambda}$ =below expected performance $\mathbf{\Lambda}$ =average performance $\mathbf{\Lambda} \boldsymbol{\Lambda}=$ superior performance $N D=n o$ data was available from this plan 


\section{Table 1}

\section{Plan Characteristics}

\begin{tabular}{|c|c|c|c|c|c|}
\hline & \multicolumn{5}{|c|}{ All Plans: (HMO/PPO/FFS) } \\
\hline & $\mathbf{N}$ & Mean & Std. Dev. & Min* & Max \\
\hline $\begin{array}{l}\text { Annual Price* }(1996) \\
\text { Employee Coverage }\end{array}$ & 132 & $\$ 477$ & $\$ 180$ & $\$ 0$ & $\$ 708$ \\
\hline $\begin{array}{l}\text { Annual Price* }(1997) \\
\text { Employee Coverage }\end{array}$ & 132 & $\$ 475$ & $\$ 193$ & $\$ 0$ & $\$ 732$ \\
\hline $\begin{array}{l}\text { Annual Price* }(1996) \\
\text { Family Coverage }\end{array}$ & 132 & $\$ 1317$ & $\$ 497$ & $\$ 0$ & $\$ 1,956$ \\
\hline $\begin{array}{c}\text { Annual Price* }(1997) \\
\text { Family Coverage }\end{array}$ & 132 & $\$ 1309$ & $\$ 527$ & $\$ 0$ & $\$ 2,004$ \\
\hline $\begin{array}{c}\text { Difference in Price (1997-1996) } \\
\text { Employee Coverage }\end{array}$ & 132 & $-\$ 2$ & $\$ 138$ & $-\$ 468$ & $\$ 252$ \\
\hline \multirow[t]{3}{*}{$\begin{array}{c}\text { Difference in Price (1997-1996) } \\
\text { Family Coverage } \\
\end{array}$} & 132 & $-\$ 8$ & $\$ 436$ & $-\$ 1,608$ & $\$ 960$ \\
\hline & \multicolumn{5}{|c|}{ HMO Plans } \\
\hline & $\mathbf{N}$ & Mean & Std. Dev & Min & Max \\
\hline Sum Superior & 106 & 2.15 & 1.78 & 0 & 6 \\
\hline Sum Average & 106 & 1.95 & 1.30 & 0 & 5 \\
\hline Sum Below Average & 106 & 1.41 & 1.30 & 0 & 5 \\
\hline Sum Missing & 106 & 0.49 & 1.09 & 0 & 5 \\
\hline Accreditation & 106 & Yes & $75(71 \%)$ & No & $31(29 \%)$ \\
\hline
\end{tabular}

*The annual prices reflect the difference between the GM price-tag and the allotted flex dollars. These prices do not include the \$504 employees receive if they decline GM-sponsored coverage. 
Table 2

Sample Distribution

\begin{tabular}{|c|c|c|c|c|}
\hline & HMO & PPO & FFS & Total \\
\hline 1996 & 25,560 & 10,906 & 33,371 & 69,837 \\
\hline 1997 & 26,909 & 10,228 & 31,146 & 68,283 \\
\hline $\begin{array}{c}\text { 1997: Tier 1 } \\
\text { (Employee) }\end{array}$ & 5,699 & 2,426 & 8,533 & 16,658 \\
\hline $\begin{array}{c}\text { 1997: Tier 2 } \\
\text { (Emp/Spouse) }\end{array}$ & 6,001 & 2,928 & 8,247 & 17,176 \\
\hline $\begin{array}{c}\text { 1997: Tier 3 } \\
\text { (Emp/Child) }\end{array}$ & 2,052 & 891 & 1,707 & 4,650 \\
\hline $\begin{array}{c}\text { 1997: Tier 4 } \\
\text { (Family) }\end{array}$ & 13,157 & 3,983 & 12,659 & 29,799 \\
\hline
\end{tabular}

Note: The universe is all active salaried employees kept in sample. 


\section{Table 3}

Frequency of 1997 Plan Choice Given 1996 Plan Choice

\begin{tabular}{|c|c|c|c|c|c|}
\hline & & \multicolumn{4}{|c|}{1997 Plan Choice } \\
\hline & & $\begin{array}{l}\text { Different } \\
\text { HMO }\end{array}$ & $\begin{array}{l}\text { Different } \\
\text { PPO }\end{array}$ & $\begin{array}{l}\text { Different } \\
\text { FFS }\end{array}$ & $\begin{array}{l}\text { Same } \\
\text { Plan }\end{array}$ \\
\hline \multirow{3}{*}{ 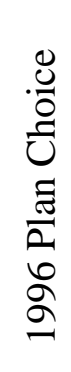 } & HMO & $5.49 \%$ & $1.01 \%$ & $2.69 \%$ & $90.9 \%$ \\
\hline & PPO & $3.68 \%$ & $0.28 \%$ & $5.46 \%$ & $90.6 \%$ \\
\hline & FFS & $4.68 \%$ & $1.86 \%$ & $3.54 \%$ & $89.9 \%$ \\
\hline
\end{tabular}

Note: The universe is all active salaried employees kept in sample who were present in both years in the same market. 


\section{Table 4}

\section{Market Characteristics}

\begin{tabular}{|c||c|c|c|c|c|}
\hline & N & Mean & Std. Dev. & Min & Max \\
\hline \hline Number of plans offered & 525 & 3.83 & 1.45 & 2 & 9 \\
\hline Number of HMO plans offered & 525 & 1.56 & 1.08 & 0 & 6 \\
\hline Number of PPO plans offered & 525 & 0.62 & 0.55 & 0 & 2 \\
\hline Number of 1996 employees & 525 & 133 & 509 & 5 & 8246 \\
\hline Number of 1997 employees & 525 & 130 & 494 & 5 & 7996 \\
\hline
\end{tabular}

Note: A market corresponds to a particular geographic area and coverage tier. 
Table 5

Coefficient Estimates

(t-statistics in parentheses)

\begin{tabular}{|c|c|c|c|}
\hline Model: & Logit & Nested Logit & Fixed effects \\
\hline Sum Superior quality $(\tilde{\beta})$ & $\begin{array}{l}0.047 \\
(8.82)\end{array}$ & $\begin{array}{l}0.037 \\
(8.18)\end{array}$ & $\begin{array}{l}0.040 \\
(8.35)\end{array}$ \\
\hline Sum Average quality $(\tilde{\beta})$ & $\begin{array}{l}0.063 \\
(7.86)\end{array}$ & $\begin{array}{l}0.050 \\
(7.67)\end{array}$ & $\begin{array}{l}0.050 \\
(7.59)\end{array}$ \\
\hline Sum Below average quality $(\tilde{\beta})$ & $\begin{array}{l}-0.045 \\
(-6.03)\end{array}$ & $\begin{array}{l}-0.020 \\
(-2.83)\end{array}$ & $\begin{array}{l}-0.013 \\
(-2.01)\end{array}$ \\
\hline Sum Missing data $(\tilde{\beta})$ & $\begin{array}{l}-0.099 \\
(-7.99)\end{array}$ & $\begin{array}{l}-0.063 \\
(-4.95)\end{array}$ & $\begin{array}{l}-0.057 \\
(-4.49)\end{array}$ \\
\hline Accredited $(\tilde{\beta})$ & $\begin{array}{l}-0.070 \\
(2.18)\end{array}$ & $\begin{array}{l}-0.031 \\
(1.17)\end{array}$ & $\begin{array}{l}-0.024 \\
(0.90)\end{array}$ \\
\hline $\begin{array}{l}\text { Price }(-\alpha) \\
(\$ 1000 s)\end{array}$ & $\begin{array}{l}-0.391 \\
(-7.64)\end{array}$ & $\begin{array}{l}-0.264 \\
(-5.67)\end{array}$ & $\begin{array}{l}-0.269 \\
(-5.61)\end{array}$ \\
\hline Prior weight $(\tilde{\mathrm{h}})$ & $\begin{array}{l}0.958 \\
(89.0)\end{array}$ & $\begin{array}{l}0.950 \\
(83.3)\end{array}$ & 1 \\
\hline $\begin{array}{l}\text { Std. dev. of random component } \\
\text { of rating }\left(\tilde{\sigma}_{v}\right)\end{array}$ & $\begin{array}{l}0.012 \\
(0.36)\end{array}$ & $\begin{array}{l}0.007 \\
(0.33)\end{array}$ & $\begin{array}{l}0.008 \\
(0.37)\end{array}$ \\
\hline $\begin{array}{l}\text { Component of error term that is } \\
\text { iid }(\lambda)\end{array}$ & 1 & $\begin{array}{l}0.583 \\
(7.56)\end{array}$ & $\begin{array}{l}0.590 \\
(7.23)\end{array}$ \\
\hline $\begin{array}{l}\text { PPO-time interaction } \\
\qquad\left(\delta_{\mathrm{PPO}, 1}\right)\end{array}$ & $\begin{array}{l}0.005 \\
(0.32)\end{array}$ & $\begin{array}{l}0.007 \\
(0.42)\end{array}$ & $\begin{array}{l}0.004 \\
(0.23)\end{array}$ \\
\hline $\begin{array}{l}\text { FFSB-time interaction } \\
\qquad\left(\delta_{\mathrm{FFSB}, 1}\right)\end{array}$ & $\begin{array}{l}-0.078 \\
(-3.37)\end{array}$ & $\begin{array}{l}-0.045 \\
(-3.05)\end{array}$ & $\begin{array}{l}-0.045 \\
(-2.99)\end{array}$ \\
\hline $\begin{array}{l}\text { Mean / std. dev. prior quality } \\
(\bar{q}) \text { for HMOs }(N=818)\end{array}$ & $\begin{array}{c}-0.514 \\
1.290\end{array}$ & $\begin{array}{c}-0.251 \\
1.058\end{array}$ & $\begin{array}{l}-0.219 \\
1.015\end{array}$ \\
\hline $\begin{array}{l}\text { Mean / std. dev. prior quality } \\
(\overline{\mathrm{q}}) \text { for PPOs }(\mathrm{N}=327)\end{array}$ & $\begin{array}{l}-0.443 \\
0.825\end{array}$ & $\begin{array}{c}-0.560 \\
0.796\end{array}$ & $\begin{array}{l}-0.568 \\
0.795\end{array}$ \\
\hline $\begin{array}{l}\text { Mean / std. dev. prior quality } \\
(\overline{\mathrm{q}}) \text { for FFSB }(\mathrm{N}=343)\end{array}$ & $\begin{array}{l}-1.656 \\
0.759\end{array}$ & $\begin{array}{l}-0.980 \\
0.445\end{array}$ & $\begin{array}{r}-0.895 \\
0.404\end{array}$ \\
\hline
\end{tabular}




\section{Table 6}

\section{Coefficient Estimates From Alternate Nested Logit Normalizations \\ (t-statistics in parentheses)}

\begin{tabular}{|c|c|c|c|}
\hline & Normalization 1 & Normalization 2 & Normalization 3 \\
\hline & $\delta_{\mathrm{HMO}, 1}=0$ & $\delta_{\mathrm{HMO}, 1}=0.101$ & $\delta_{\mathrm{HMO}, 1}=0.143$ \\
\hline Sum Superior quality $(\tilde{\beta})$ & $\begin{array}{l}0.037 \\
(8.18)\end{array}$ & $\begin{array}{l}0.020 \\
(4.42)\end{array}$ & $\begin{array}{l}0.013 \\
(2.86)\end{array}$ \\
\hline Sum Average quality $(\tilde{\beta})$ & $\begin{array}{l}0.050 \\
(7.67)\end{array}$ & $\begin{array}{l}0.033 \\
(5.10)\end{array}$ & $\begin{array}{l}0.026 \\
(4.03)\end{array}$ \\
\hline Sum Below average quality $(\tilde{\beta})$ & $\begin{array}{l}-0.020 \\
(-2.83) \\
\end{array}$ & $\begin{array}{l}-0.037 \\
(-5.16) \\
\end{array}$ & $\begin{array}{l}-0.044 \\
(-6.13) \\
\end{array}$ \\
\hline Sum Missing data $(\tilde{\beta})$ & $\begin{array}{l}-0.063 \\
(-4.95)\end{array}$ & $\begin{array}{l}-0.080 \\
(-6.27)\end{array}$ & $\begin{array}{l}-0.087 \\
(-6.82)\end{array}$ \\
\hline Accredited $(\tilde{\beta})$ & $\begin{array}{r}-0.031 \\
(1.17) \\
\end{array}$ & $\begin{array}{l}-0.031 \\
(1.17) \\
\end{array}$ & $\begin{array}{r}-0.031 \\
(1.17) \\
\end{array}$ \\
\hline $\begin{array}{l}\text { Price }(\alpha) \\
(\$ 1000 s)\end{array}$ & $\begin{array}{l}-0.264 \\
(-5.67)\end{array}$ & $\begin{array}{l}-0.264 \\
(-5.67)\end{array}$ & $\begin{array}{l}-0.264 \\
(-5.67)\end{array}$ \\
\hline Prior weight $(\tilde{h})$ & $\begin{array}{l}0.950 \\
(83.3)\end{array}$ & $\begin{array}{l}0.950 \\
(83.3)\end{array}$ & $\begin{array}{l}0.950 \\
(83.3)\end{array}$ \\
\hline $\begin{array}{l}\text { Std. dev. of random component } \\
\text { of rating }\left(\tilde{\sigma}_{v}\right)\end{array}$ & $\begin{array}{l}0.007 \\
(0.33) \\
\end{array}$ & $\begin{array}{l}0.007 \\
(0.33) \\
\end{array}$ & $\begin{array}{l}0.007 \\
(0.33) \\
\end{array}$ \\
\hline $\begin{array}{c}\text { Component of error term that is } \\
\text { iid }(\lambda)\end{array}$ & $\begin{array}{l}0.583 \\
(7.56)\end{array}$ & $\begin{array}{l}0.583 \\
(7.56)\end{array}$ & $\begin{array}{l}0.583 \\
(7.56)\end{array}$ \\
\hline $\begin{array}{c}\text { PPO-time interaction } \\
\left(\delta_{\mathrm{PPO}, 1}\right)\end{array}$ & $\begin{array}{l}0.007 \\
(0.42)\end{array}$ & $\begin{array}{l}0.007 \\
(0.42)\end{array}$ & $\begin{array}{l}0.007 \\
(0.42)\end{array}$ \\
\hline $\begin{array}{l}\text { FFSB-time interaction } \\
\qquad\left(\delta_{\mathrm{FFSB}, 1}\right)\end{array}$ & $\begin{array}{l}-0.045 \\
(-3.05)\end{array}$ & $\begin{array}{l}-0.045 \\
(-3.05)\end{array}$ & $\begin{array}{l}-0.045 \\
(-3.05)\end{array}$ \\
\hline $\begin{array}{l}\text { Mean / std. dev. prior quality } \\
(\overline{\mathrm{q}}) \text { for HMOs }(\mathrm{N}=818)\end{array}$ & $\begin{array}{c}-0.251 \\
1.058\end{array}$ & $\begin{array}{c}-0.251 \\
1.058\end{array}$ & $\begin{array}{c}-0.251 \\
1.058\end{array}$ \\
\hline $\begin{array}{l}\text { Mean / std. dev. prior quality } \\
(\overline{\mathrm{q}}) \text { for PPOs }(\mathrm{N}=327)\end{array}$ & $\begin{array}{c}-0.560 \\
0.796\end{array}$ & $\begin{array}{l}-0.560 \\
0.796\end{array}$ & $\begin{array}{c}-0.560 \\
0.796\end{array}$ \\
\hline $\begin{array}{l}\text { Mean / std. dev. prior quality } \\
(\overline{\mathrm{q}}) \text { for FFSB }(\mathrm{N}=343)\end{array}$ & $\begin{array}{l}-0.980 \\
0.445\end{array}$ & $\begin{array}{l}-0.980 \\
0.445\end{array}$ & $\begin{array}{c}-0.980 \\
0.445\end{array}$ \\
\hline
\end{tabular}




\section{Table 7}

\section{Effect of Ratings on Plan Choice}

\begin{tabular}{|c|c|c|c|}
\hline & Norm 1 & Norm 2 & Norm 3 \\
\hline $\begin{array}{c}\text { (1) Change in HMO market share } \\
\text { if no ratings released }\end{array}$ & $0.21 \%$ & $2.15 \%$ & $2.97 \%$ \\
\hline $\begin{array}{c}\text { (2) Change in HMO market share } \\
\text { if all HMOs had average ratings }\end{array}$ & $6.60 \%$ & $6.60 \%$ & $6.60 \%$ \\
\hline $\begin{array}{c}\text { (3) Change in HMO market share } \\
\text { if all HMOs had 5 average ratings } \\
\text { and 1 below average rating }\end{array}$ & $5.18 \%$ & $5.18 \%$ & $5.18 \%$ \\
\hline $\begin{array}{c}\text { (4) Change in HMO market share } \\
\text { given actual ratings }\end{array}$ & $2.81 \%$ & $2.81 \%$ & $2.81 \%$ \\
\hline $\begin{array}{c}\text { Difference between (2) and (1) } \\
\text { Difference between (3) and (1) }\end{array}$ & $6.39 \%$ & $4.45 \%$ & $3.63 \%$ \\
\hline Difference between (4) and (1) & $2.60 \%$ & $0.66 \%$ & $-0.16 \%$ \\
\hline
\end{tabular}

Note: The table reports the change in the total share of GM employees choosing HMOs relative to the 1996 levels: All figures are computed using the estimated parameters of the model. 


\section{Table 8}

Value of Ratings

\begin{tabular}{|c||c|c|c|}
\hline & Normalization 1 & Normalization 2 & Normalization 3 \\
\hline \hline $\begin{array}{c}\text { Mean value for one } \\
\text { year of coverage }\end{array}$ & $\$ 16$ & $\$ 10$ & $\$ 10$ \\
\hline $\begin{array}{c}\text { Percent of employees } \\
\text { who switch plans as a } \\
\text { result of the ratings }\end{array}$ & $4.26 \%$ & $3.13 \%$ & $3.00 \%$ \\
\hline $\begin{array}{c}\text { Percent who switch } \\
\text { from one HMO to } \\
\text { another as a result of } \\
\text { the ratings }\end{array}$ & $1.27 \%$ & $1.34 \%$ & $1.35 \%$ \\
\hline $\begin{array}{c}\text { Percent who switch to } \\
\text { an HMO from a non- } \\
\text { HMO as a result of the } \\
\text { ratings }\end{array}$ & $2.78 \%$ & $1.23 \%$ & \\
\hline $\begin{array}{c}\text { Percent who switch } \\
\text { from an HMO to a } \\
\text { non-HMO as a result } \\
\text { of the ratings }\end{array}$ & $0.21 \%$ & $0.57 \%$ & $0.75 \%$ \\
\hline
\end{tabular}

Note: All figures are computed using the estimated parameters of the model. 


\section{Figure 2}

Relationship between prior and signal, nested logit model

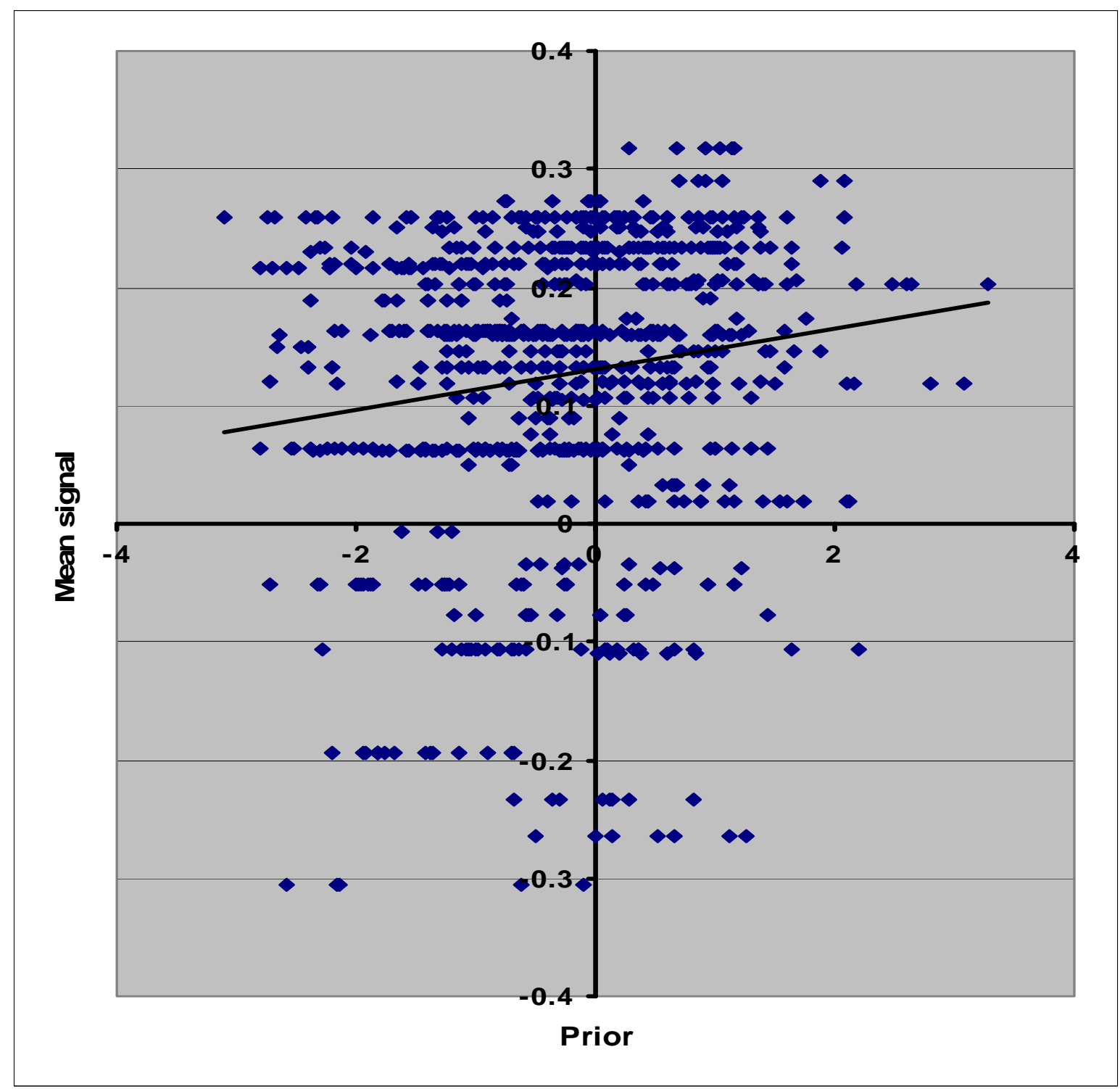

Note: The figure reports the prior mean quality and the mean signal for each HMO in each market, as well as a fitted linear regression trend line. 